\title{
A self-fertile species of Steinernema from Indonesia: further evidence of convergent evolution amongst entomopathogenic nematodes?
}

\author{
C. T. GRIFFIN*, K. M. O’ CALLAGHAN and I. DIX \\ Institute of Bioengineering and Agroecology, and Department of Biology, National University of Ireland Maynooth, \\ Maynooth, Co. Kildare, Ireland
}

(Received 8 March 2000; revised 14 August 2000; accepted 14 August 2000)

\section{S U M M A R Y}

More than 20 species of the entomopathogenic nematode Steinernema have been described; to date, all reproduce exclusively by cross-fertilization of male and female individuals. Steinernema sp. strain T87 from Indonesia was found to consist largely of self-fertile hermaphrodites. Progeny were produced by morphological females both in insects (Galleria mellonella) and in hanging drops of insect haemolymph inoculated with a single infective juvenile. Sperm were present in the oviduct of unmated morphological females. Approximately $1 \%$ of infective juveniles developed into males, and males were also present in the second generation where they constituted $1-6 \%$ of the population. Under the same conditions the related species Steinernema longicaudum strain CB2B displayed typical steinernematid reproduction: crossfertilization and a 1:1 sex ratio. It is argued that the development of hermaphroditism in Steinernema sp. T87 represents convergent evolution with Heterorhabditis, the other major genus of entomopathogenic nematode.

Key words: evolution, hermaphrodite, nematode, reproduction, self-fertilization, sex determination.

\section{INTRODUCTION}

Entomopathogenic nematodes of the genera Steinernema Travassos 1927 and Heterorhabditis Poinar 1976 have, in recent decades, become commercially successful for the biological control of insect pests. This has stimulated intensive research into all aspects of the biology of these nematodes, and a search for novel genotypes in many countries worldwide. Twenty-three species of Steinernema and 7 of Heterorhabdtitis have been described (Hominick et al. 1997, 1999). The life-cycle of the 2 genera is similar: the infective juvenile, a specialized 3rd-stage juvenile, is the free-living stage and is normally found in soil. It enters a living insect and releases symbiotic bacteria, either Xenorhabdus spp. (Steinernema spp.) or Photorhabdus spp. (Heterorhabditis spp.). The bacteria kill the host and the developing nematodes feed on them and on the digested insect tissues. The nematodes go through 2 or more generations, producing new infective juveniles which emerge into the soil as host resources are depleted. The 2 genera are not closely related (Blaxter et al. 1998); similarities in patterns of infectivity, life-cycle and association with a bacterial symbiont are considered to be the result of convergent evolution (Poinar, 1993). A major difference between the two genera is that in Heterorhabditis, the

* Corresponding author: Tel: +353 1708 3841. Fax: +353 1708 3845. E-mail: christine.griffin@may.ie infective juveniles always develop into self-fertile hermaphrodites, while in Steinernema they develop into cross-fertilizing females or males (Poinar, 1979, 1990).

The T87 nematode strain, of which several isolates were recovered from the Moluccan islands of Indonesia, displayed an RFLP profile which clearly identified it as a Steinernema sp. The named species with the closest RFLP pattern to that of Steinernema sp. T87 is Steinernema longicaudum Shen \& Wang 1992 (Griffin et al. 2000). During cross-breeding studies to clarify the taxonomic position of Steinernema T87, evidence was found of uniparental reproduction by this strain. Most nematodes are bisexual cross-fertilizing organisms. Hermaphroditic and parthenogenetic forms are common in some groups including the Rhabditida (Triantaphyllou \& Hirschmann, 1964), but we know of no unequivocal evidence of this in the Steinernematidae. We here report on the mode of reproduction in Steinernema T87.

MATERIALS AND METHODS

\section{Nematodes}

Steinernema sp. INA S22 (displaying the T87 RFLP type) originated on the island of Seram in the Indonesian archipeligo (Griffin et al. 2000). Steinernema longicaudum strain CB2B originated in China and was obtained from $\mathrm{Mr} \mathrm{B}$. Briscoe, CABI 
Table 1. Reproduction of Steinernema spp. in Galleria mellonella larvae exposed to 1 or 2 infective juveniles (IJs)

\begin{tabular}{llllll}
\hline \hline & \multicolumn{2}{l}{ No. of insects } & \\
\cline { 3 - 4 } Nematode strain & No. of IJs & Exposed & Dead & $\begin{array}{l}\text { With reproducing } \\
\text { nematodes }\end{array}$ & $\begin{array}{l}\text { Proportion of insects with } \\
\text { reproducing nematodes }\end{array}$ \\
\hline Steinernema sp. T87 & 1 & 60 & 42 & 28 & $0 \cdot 87 * * *$ \\
S. longicaudum CB2B & 2 & 47 & 45 & 41 & 0 \\
& 2 & 40 & 26 & 0 & $0 \cdot 35$ \\
\hline \hline
\end{tabular}

Asterisks indicate a significant difference from expected proportion of $0 \cdot 5$ : *** $P<0 \cdot 001$ (Chi square, 1 D.F.).

Bioscience, UK. They were cultured in late instar larvae of the wax moth Galleria mellonella (Mealworm Company, Sheffield, UK) at $28-30^{\circ} \mathrm{C}$. Emerging nematodes were harvested in modified White traps. Infected cadavers were placed on moist filter paper in small $(4.5 \mathrm{~cm}$ diam.) Petri dishes which were placed uncovered in sealed plastic food containers containing water to a depth of $0.5 \mathrm{~cm}$. The emerging nematodes migrated up the side of the Petri dish and down into the water. Standard White traps were unsuccessful for the Indonesian strain of Steinernema, as pre-infective and adult stages migrate into the trap in large numbers. Harvested IJs were washed 3 times by sedimentation in tap water and stored in water at $20^{\circ} \mathrm{C}$.

\section{In vivo reproduction}

Late instar $G$. mellonella larvae were exposed individually to 1 or $2 \mathrm{IJs}$ in $1.5 \mathrm{ml}$ microfuge tubes with a ventilation hole in the lid. Each tube was lined with filter paper moistened with $150 \mu \mathrm{l}$ of tap water. A single nematode IJ was picked out from dilute aqueous suspension and placed in a drop of water in a watch glass, from which it was transferred in a small volume of water (approx $20 \mu \mathrm{l}$ ) to the moist filter paper in the tube. Both operations were carried out under a dissecting microscope (Zeiss MS5 Stereomicroscope) at $\times 10$ magnification, using a Gilson pipette. A clean pipette tip was used for each transfer. Where 2 IJs were used, each was transferred individually. An insect was added to each tube, and tubes were incubated at $28-30{ }^{\circ} \mathrm{C}$. The filter paper was moistened at intervals as necessary. Insects were then either dissected in Ringer's saline or observed for emerging nematodes. Dissections were performed after at least 5 (T87) or 10 (CB2B) days.

\section{In vitro reproduction}

IJs were surface sterilized in $0.4 \%$ hyamine and washed 5 times in sterile distilled water. Single IJs were transferred to hanging drops of $G$. mellonella blood (Poinar, 1967). Pairs were established by transferring a male into a drop containing a morphological female once they could be differentiated. For T87, first or second generation males from cadavers or hanging drops were used.

\section{Light microscopy}

Observations and photographs were made using an inverted Nikon Diaphot microscope equipped for Nomarski differential interference observation. Morphological female nematodes that had developed individually in hanging drops were transferred to a drop of M9 buffer (Brenner, 1974) and the reproductive tract was dissected using fine needles.

RESULTS

\section{Reproduction}

Steinernema sp. T87 reproduced both in G. mellonella that had been exposed to a single $\mathrm{IJ}$, and in hanging drops of $G$. mellonella haemolymph containing a single morphological female. Almost half of the exposed G. mellonella (67\% of the killed insects) contained nematode progeny (Table 1 ).

No progeny were produced by single nematodes of S. longicaudum CB2B either in vivo (Table 1) or in vitro (Table 2). Progeny were produced when 2 nematodes were present, indicating that conditions were suitable for reproduction of the species both in vivo and in vitro. Of the insects exposed to $2 \mathrm{~S}$. longicaudum IJs, $35 \%$ contained progeny, a proportion not significantly different from the $50 \%$ expected for an amphimictic species, and all of the mixed-sex pairs of the species in hanging drops produced offspring. By comparison, $87 \%$ of the insects exposed to 2 Steinernema sp. T87 contained progeny, a proportion deviating to a highly significant $(P<0 \cdot 001)$ degree from the expected.

\section{Sex ratio}

In $G$. mellonella the sex ratio of first generation $S$. longicaudum was approximately balanced, while only 
Table 2. Reproduction of Steinernema spp. in hanging drops of Galleria mellonella haemolymph containing either a female or a male and a female nematode

\begin{tabular}{lll}
\hline \hline Strain & No. of nematodes/drop & $\begin{array}{l}\text { No. of drops with } \\
\text { progeny/total }\end{array}$ \\
\hline Steinernema sp. T87 & Female & $30 / 39$ \\
& Female + male & $20 / 24$ \\
S. longicaudum CB2B & Female & $0 / 19$ \\
& Female +male & $9 / 9$ \\
\hline \hline
\end{tabular}

Table 3. Mean ( \pm s.E.) number and percentage of male and female worms of Steinernema spp.: first generation in Galleria mellonella larvae with low $(<20)$, medium $(21-100)$ and high $(>100)$ infestation levels; second generation in G. mellonella cadavers and in hanging drops of G. mellonella haemolymph ( $n=$ number of $G$. mellonella or hanging drops.)

\begin{tabular}{|c|c|c|c|c|c|c|c|}
\hline \multirow[b]{2}{*}{ Species/strain } & \multirow[b]{2}{*}{ Generation } & \multirow[b]{2}{*}{ Infestation level } & \multicolumn{2}{|l|}{ Females } & \multicolumn{2}{|l|}{ Males } & \multirow[b]{2}{*}{$n$} \\
\hline & & & Number & $\%$ & Number & $\%$ & \\
\hline S. longicaudum CB2B & $1 \mathrm{st}$ & Medium & $43 \pm 11$ & $49 \pm 3$ & $44 \pm 7$ & $51 \pm 3$ & 3 \\
\hline \multirow{7}{*}{ Steinernema sp. T87 } & $1 \mathrm{st}$ & Low & $14 \pm 2$ & $99 \pm 0 \cdot 8$ & $0 \cdot 1 \pm 0 \cdot 1$ & $1 \pm 0 \cdot 2$ & 7 \\
\hline & & Medium & $44 \pm 4$ & $99 \pm 0 \cdot 4$ & $0 \cdot 4 \pm 0 \cdot 1$ & $1 \pm 0 \cdot 4$ & 14 \\
\hline & & High & $237 \pm 62$ & $99 \pm 0$ & $3 \pm 1$ & $1 \pm 0$ & 3 \\
\hline & $2 \mathrm{nd}$ & Single* & $164 \pm 56$ & $95 \pm 1 \cdot 9$ & $5 \pm 2 \cdot 5$ & $5 \pm 1.9$ & 7 \\
\hline & & High* & $203 \pm 11$ & $94 \pm 4 \cdot 0$ & $15 \pm 11$ & $6 \pm 4 \cdot 0$ & 3 \\
\hline & & Single female $\uparrow$ & $402 \pm 53$ & $99 \pm 0 \cdot 3$ & $3 \pm 1 \cdot 4$ & $0 \cdot 6 \pm 0 \cdot 3$ & 6 \\
\hline & & Female + male $\dagger$ & $418 \pm 46$ & $98 \pm 0 \cdot 3$ & $6 \pm 0 \cdot 9$ & $1 \cdot 7 \pm 0 \cdot 3$ & 16 \\
\hline
\end{tabular}

* Based on a sample of the total population in the G. mellonella cadaver.

$\uparrow$ In hanging drop of G. mellonella haemolymph.

$1 \%$ of first generation T87 strain nematodes were male (Table 3). The T87 sex ratio was similar at 3 infection intensities, ranging from less than 20 to over 100 nematodes/insect (Table 3). When alone, either in hanging drops or in vivo, approximately $6 \%$ of the T87 IJs developed into males (singly-infected G. mellonella: 34 females and 2 males; single IJs in hanging drops: 33 females and 2 males). Of the second generation worms, $1-2 \%$ of those developing in hanging drops were male, and $5-6 \%$ of those sampled from G. mellonella.

\section{Light microscope observations}

Sperm were observed in the uterus amongst developing embryos of unmated first generation females of Steinernema sp. T87, that had been reared alone in hanging drops of G. mellonella haemolymph (Fig. 1).

\section{DISCUSSION}

The findings presented here clearly show that Steinernema sp. T87 is self-fertile. The presence of sperm in the reproductive tract of unmated first generation morphological females indicates that the mode of reproduction is by hermaphroditism. Unlike Heterorhabditis, where first generation parasites consist entirely of self-fertile hermaphrodites and the second generation of males and females, males of T87 are present in both generations at a low level - a situation more typical of Caenorhabditis elegans (Hodgkin, 1988). In T87, males represented 1-6\% of the population. On the other hand, the balanced $(1: 1)$ sex ratio reported here for $S$. longicaudum CB2B is typical of the genus (Danilov, 1976; Nguyen \& Smart, 1992; Selvan, Campbell \& Gaugler, 1993) and of strictly bisexual, cross-fertilizing nematode species in general (Triantaphyllou \& Hirschmann, 1964).

This is the first documentation of hermaphroditism in a strain of Steinernema. Hsiao \& Choo (1996) reported parthenogenetic development in 3 strains of Steinernema carpocapsae. However, 2 of the 3 strains, DD-136 and All, are extensively used in other laboratories and to our knowledge reproduction of those strains is normally by crossfertilization. Cross-breeding studies have been widely used in resolving taxonomic relationships of steinernematids. Such studies frequently include strains of $S$. carpocapsae (e.g. Nguyen \& Smart, 1990; Elawad, Ahmad \& Reid, 1997; Stock, Choo \& Kaya, 1997), and have not confirmed that this species is capable of parthenogenetic reproduction. 


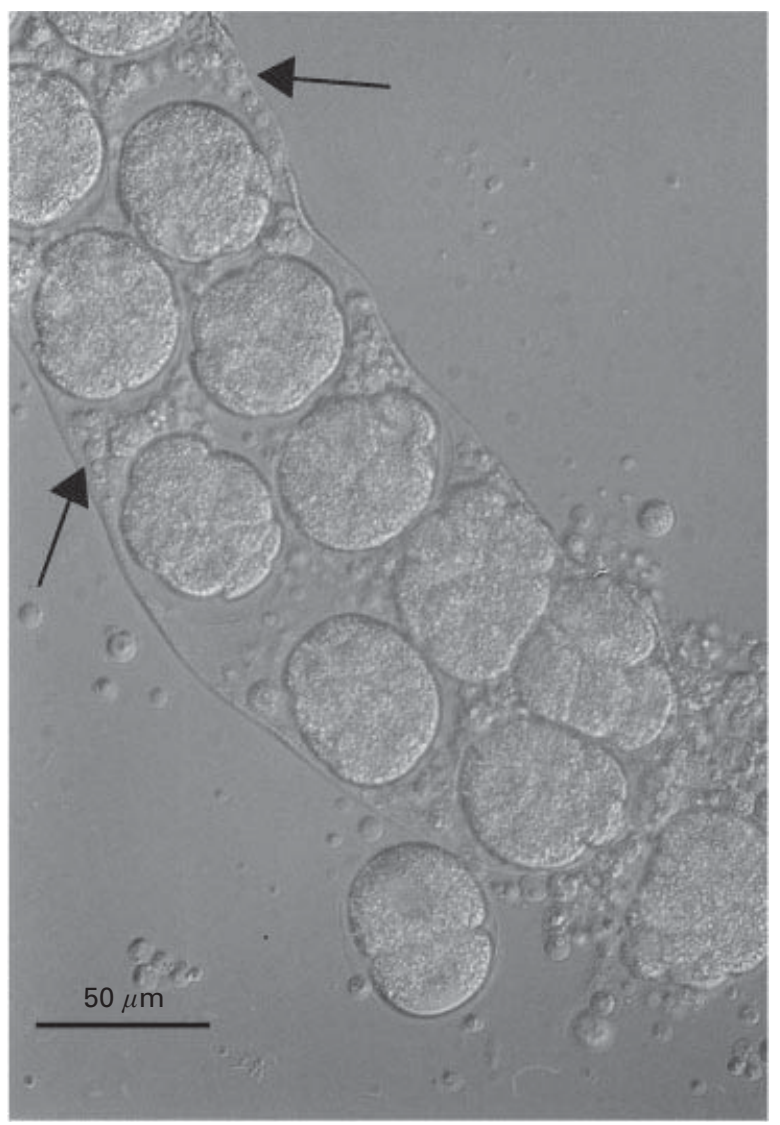

Fig. 1. A portion of the uterus dissected from an unmated Steinernema sp. T87 hermaphrodite showing sperm (indicated by arrows) and ova.

The All strain, 1 of the 3 used by Hsiao \& Choo (1996), was included in cross-breeding studies by Poinar (1989) and by Stock, Somsook \& Reid (1998) and failed to reproduce without males of the same species. DD-136, another of the strains reported by Hsiao \& Choo (1996) to be parthenogenetic, has been widely used in research since its isolation in 1954, and also failed to reproduce in the absence of males (e.g. Poinar, 1967). The finding of Hsiao \& Choo (1996) regarding parthenogenetic reproduction in all $3 S$. carpocapsae strains tested thus requires verification. It is clear that, if that species is capable of parthenogenesis, it is not the normal mode of reproduction. The existence of self-fertile strains of Steinernema such as T87 points to the need for single worm (IJ or female) controls when carrying out crosses for species determination. Alternatively, crosses should utilize males of the novel strains with females of strains known to require cross-fertilization.

In Steinernema T87, as in Heterorhabditis, a single invading IJ can colonize an insect, which would be an advantage to a species in which IJs are characteristically alone on invasion. Hermaphroditism also has the benefit of reducing the cost of sexual reproduction, which has been described as the cost of producing males (Maynard Smith, 1978) or the cost of meiosis (Williams, 1975), where a parent provides only half of its progeny's genes. It is believed that in nematodes both hermaphroditism and parthenogenesis evolved from the bisexual or gonochoristic condition (Triantaphyllou \& Hirschmann, 1964). On this basis it is likely that T87 evolved from a bisexual strain of Steinernema, representing a further example of convergent evolution between steinernematids and heterorhabditids (Poinar, 1993).

We might expect that entomopathogenic nematodes with self-fertile infective juveniles (i.e. heterorhabditids and Steinernema T87) should occur in similar ecological conditions, and perhaps possess a similar suite of adaptations. If hermaphroditism results from selection where host individuals are each encountered by relatively few IJs, we must look to conditions in which there is low local IJ density. Several factors could lead to this; for example, the production of low numbers of IJs per host cadaver (e.g. from very small insects), poor survival of $\mathrm{IJ}$ s, or fresh hosts occurring at a distance from source hosts, necessitating wide dispersal of IJs. Unfortunately, nothing is known of the hosts naturally used by Steinernema sp. T87, as it was isolated from soil samples by baiting (Griffin et al. 2000).

The mode of reproduction in all known species of Heterorhabditis is similar, with self-fertile hermaphrodites developing from infective juveniles and being succeeded by one or more bisexual generations. It is thus likely that this is the ancestral mode of reproduction of the genus. It may have arisen just once, possibly after the adoption of the entomopathogenic life-style. On the other hand, as several freeliving relatives of Heterorhabditis, including $C$. elegans and several species of Rhabditis, reproduce largely as hermaphrodites ('Triantaphyllou \& Hirschmann, 1964) this condition may have arisen in Heterorhabditis prior to its association with insects, pre-adapting the genus to conditions in which it needed to survive low characteristic abundance.

Considering the advantages of hermaphroditism and its ubiquity in the entomopathogenic heterorhabditids, why have other hermaphroditic steinernematids not been reported? Of course, it is very possible that other self-fertile species of Steinernema exist. There are 23 described species, and at least an equal number of new species as yet undescribed (Hominick et al. 1999), but the biology of only a handful has been studied in any detail. Nevertheless, it would seem that hermaphroditism is rare among steinernematids. In order for reproduction by self-fertilization to evolve, the advantages must outweigh any possible disadvantage of inbreeding. One of the hypothesized benefits of sexual reproduction is that the production of genetically variable progeny is an advantage in the co-evolutionary arms race with parasites and pathogens (the Red Queen hypothesis (Van Valen, 1973)). Bisexual steinernematids, with more frequent cross- 
fertilization, should be able to evolve more rapidly than heterorhabditids or T87, and thus be better able to evolve ahead of their enemies. However, theoretical models suggest that in animals that reproduce largely by self-fertilization, even small amounts of outcrossing can offset the genetic disadvantages of inbreeding and maintain a rapid rate of evolution (Green \& Noakes, 1995). This may explain why heterorhabditids do not need to be entirely bisexual but it does not explain why steinernematids largely are. Either the necessary mutations in the sex determination pathway have not arisen, or other features of steinernematid biology swing the balance of advantage in favour of outcrossing. The challenge is to discern what those features might be.

In Heterorhabditis, the production of males in the second parasitic generation, where they represent 6-38\% of the population (Dix et al. 1994; Koltai, Glazer \& Segal, 1995; Strauch, Stoessel \& Ehlers, 1994) provides the opportunity for cross-fertilization. While many of these matings may be sib-sib, crosses with more distant relatives may occur in the second generation if an insect is invaded by 2 or more IJs. The percentage of males recorded here in Steinernema T87 was rather low by comparison with heterorhabditids, varying from less than 1 to $6 \%$, but their presence in the first parasitic generation could provide increased opportunity for outcrossing. However, assuming that hermaphroditism is of benefit in circumstances in which hosts are frequently colonized by a single nematode, T87 IJs that develop into males may frequently fail to reproduce, and their occurrence seems to represent an inferior reproductive strategy to that of Heterorhabditis, where every IJ that establishes in a host can reproduce.

The occurrence of self-fertility in Steinernema T87 raises a number of interesting questions (1) Do the males accomplish useful outbreeding in nature? (2) Do male IJs have strategies that enhance their chances of reproducing, e.g. by only entering a host already parasitized by a conspecific hermaphrodite? (3) Is the level of outbreeding encountered in Heterorhabditis and Steinernema a true reflection of fitness requirements rather than evolutionary chance?

We are grateful to Professor Martin Downes for his helpful comments on the manuscript.

\section{REFERENCES}

BlaXter, M. L., DE LEY, P., GAREY, J. R., LiU, L. X., SCHELdEMAN, P., VIERSTRAETE, A., VANFLETEREN, J. R., MACKEY, L. Y., DORRIS, M., FRISSE, L. M., VIDA, J. T. \& THOMAs, W. K. (1998). A molecular evolutionary framework for the phylum Nematoda. Nature, London 395, 71-75.
BRENNER, s. (1974). The genetics of Caenorhabditis elegans. Genetics 77, 71-94.

DANilOv, L. G. (1976). The effect of temperature on the susceptibility of Galleria mellonella to infection by Neoaplectana carpocapsae Weiser, 1995 'agriotos' strain, and on the development of the nematode in the insect host. Byulleten' Vsesoyuznogo Nauchno Issledovatel'skogo Instituta Zashchity Rastenii 37, 17-21.

DiX, I., KOltai, H., Glazer, I. \& BURNEll, A. M. (1994). Sperm competition in mated first and second generation hermaphrodite females of the HP88 strain of Heterorhabditis (Nematoda: Heterorhabditidae) and progeny sex ratios in mated and unmated females. Fundamental and Applied Nematology 17, 17-27.

ElaWAD, s., AHMAD, W. \& REID, A. P. (1997). Steinernema abbasi sp. n. (Nematoda: Steinernematidae) from the Sultanate of Oman. Fundamental and Applied Nematology 20, 435-442.

GREEN, R. F. \& NOAKES, D. L. G. (1995). Is a little bit of sex as good as a lot? Fournal of Theoretical Biology 174, 87-96.

GRIFFIN, C. T., CHAERANI, R., FALlON, D., REID, A. P. \& DOWNEs, M. J. (2000). Occurrence and distribution of the entomopathogenic nematodes Steinernema spp. and Heterorhabditis indica in Indonesia. Fournal of Helminthology 74, 143-150.

Hodgkin, J. (1988). Sexual dimorphism and sex determination. In The Nematode Caenorhabditis elegans (ed. Wood, W. B.), pp. 243-279. Cold Spring Harbor Laboratory Press, New York.

HOMINICK, W. M., BRISCOE, B. R., PINO, F. G. DEL, JIAN, H., HUNT, D. J., KOzOdOY, E., MRACEK, Z., NGUYEN, K. B., REID, A. P., SPIRIDONOV, S., STOCK, P., STURHAN, D., WAturu, C. \& Yoshida, M. (1997). Biosystematics of entomopathogenic nematodes: current status, protocols and definitions. Fournal of Helminthology 71, 271-298.

HOMINICK, W. M., HUNT, D. J., REID, A. P., BRISCOE, B. R. \& BOHAN, D. A. (1999). Biosystematics, phylogeny and population genetics of entomopathogenic nematodes. In Taxonomy, Phylogeny and Gnotobiological Studies of Entomopathogenic Nematode Bacterium Complexes (ed. Boemare, N. Richardson, P. \& Coudert, F.), pp. 45-53. European Commission, Brussels-Luxembourg. HSIAO, W.-F. \& CHOO, L.-K. (1996). Parthenogenetic reproduction by the entomopathogenic nematode, Steinernema carpocapsae (Nematoda: Steinernematidae), on poultry egg yolk or Galleria larva. Zoological Studies 35, 227-229.

KOLTAI, H., GLAZER, I. \& SEGAL, D. (1995). Reproduction of the entomopathogenic nematode Heterorhabditis bacteriophora Poinar, 1976: hermaphroditism vs amphimixis. Fundamental and Applied Nematology 18, 55-61.

Maynard smith, J. (1978). The Evolution of Sex. Cambridge University Press, Cambridge.

NGUYEN, K. B. \& SMART, G. C. (1990). Steinernema scapterisci n. sp. (Rhabditida: Steinernematidae). Fournal of Nematology 22, 187-199.

NGUYEN, K. B. \& SMART, G. C. (1992). Life cycle of Steinernema scapterisci Nguyen \& Smart, 1990. Journal of Nematology 24, 160-169. 
POINAR, G. O. Jr. (1967). Description and taxonomic position of the DD-136 nematode (Steinernematidae, Rhabditoidea) and its relationship to Neoaplectana carpocapsae Weiser. Proceedings of the Helminthological Society of Washington 34, 199-209.

POINAR, G. O. Jr. (1979). Nematodes for Biological Control of Insects. CRC Press, Boca Raton, Florida.

POINAR, G. O. Jr. (1989). Examination of the neoaplectanid species Steinernema feltiae Filipjev carpocapsae Weiser and bibionis Bovien (Nematoda: Rhabditida). Revue de Nématologie 12, 375-377.

POINAR, G. O. Jr. (1990). Taxonomy and biology of Steinernematidae and Heterorhabditidae. In Entomopathogenic Nematodes in Biological Control (ed. Gaugler, R. \& Kaya, H. K.), pp. 23-61. CRC Press, Boca Raton, Florida.

POINAR, G. O. Jr. (1993). Origins and phylogenetic relationships of the entomophilic rhabditids, Heterorhabditis and Steinernema. Fundamental and Applied Nematology 16, 333-338.

selvan, s., Campbell, J. F. \& Gaugler, R. (1993). Density dependent effects on entomopathogenic nematodes
(Heterorhabditidae and Steinernematidae) within an insect host. Fournal of Invertebrate Pathology 62, 278-284.

STOCK, S. P., CHOO, H. Y. \& KAYA, H. K. (1997). An entomopathogenic nematode, Steinernema monticolum sp. n. (Rhabditida: Steinernematidae) from Korea with a key to other species. Nematologica 43, 15-29. STOCK, S. P., SOMSOOK, V. \& REID, A. P. (1998).

Steinernema siamkayai $\mathrm{n}$. sp. (Rhabditida:

Steinernematidae), an entomopathogenic nematode from Thailand. Systematic Parasitology 41, 105-113.

Strauch, O., STOESSEL, S. \& EHLERS, R.-U. (1994). Culture conditions define automictic or amphimictic rhabditid nematodes of the genus Heterorhabditis. Fundamental and Applied Nematology 17, 575-582.

TRIANTAPHYlloU, A. C. \& HIRSCHMANN, H. (1964).

Reproduction in plant and soil nematodes. Annual Review of Phytopathology 2, 57-80.

VAN VALEN, L. (1973). A new evolutionary law. Evolutionary Theory 1, 1-30.

williams, G. C. (1975). Sex and Evolution. Princeton University Press, Princeton, New Jersey. 